\title{
INFLUENCE ANALYSIS OF LAND USE BY POPULATION GROWTH ON URBAN FLOOD RISK USING SYSTEM DYNAMICS
}

\author{
GIBYUNG PARK \& HEEKYUNG PARK \\ Department of Civil and Environmental Engineering, KAIST, Republic of Korea
}

\begin{abstract}
Urban flood is occurring frequently because of recent local torrential rainfalls, climate change and the problem of urbanization. In many studies, hydrological changes in urban areas due to the increase of impervious areas are the main causes of urban flood. However, there are insufficient studies to address the problem of population growth, which is the root cause of the increase in impervious areas by urbanization. So, in this paper, we focus on population growth in the urban flood problem and investigate the effect of land use on the urban flood from the increase in population. As a methodology, we used a system dynamics approach using a feedback method with causal loop, which is suitable for modeling natural phenomena such as population growth and urbanization. Through this methodology, we have developed a system dynamics model that calculates urban flood risk. The urban flood risk varies with population growth, urban expansion, and land use. In addition, the scenario was constructed based on the population and land use data of Yangsan City, a new city in Korea. The sensitivity was analyzed through simulation. Based on the results of the sensitivity analysis, we propose a land use regulation direction to reduce the risk of urban flood in new cities that are undergoing urbanization by population growth.

Keywords: urban flood, system dynamics, impervious area, population growth, urbanization, land use.
\end{abstract}

\section{INTRODUCTION}

Urban flood is occurring frequently due to recent local torrential rainfalls by climate change and the problem of urbanization. In many studies, hydrological changes in urban areas due to the increase of impervious area are the main causes of urban flood [1]. However, more research focused on climate change and hydrological changes rather than urbanization problems: a study on reservoir management for flood management [2]; analysis of urban drainage systems to cope with floods [3]; a study on the risk of flooding in response to climate change due to increased atmospheric $\mathrm{CO}_{2}$ concentration [4]; and a study on the hydrological change analysis in urban land use change [5]. These studies are mainly focused on climate and hydrological changes in urban floods.

Numerous studies and data have shown that the increase in impervious area is recognized to be the main cause of urban flood. We need to think more about the root cause of the urban flood. Land use change by population growth and urbanization is the root cause of hydrological changes and urban flood [6]. However, there are few studies to solve the hydrological problems caused by population growth which is the root cause of the urban flood. There is an analysis of the relationship between land use change by population growth and natural hazards damages, but that did not use system dynamics approach [7].

So, in this paper, we focus on the problem of urbanization in urban flood and find its solution. Expansion of city due to population growth, the impervious area changes as development progresses and change in land use by population growth are natural phenomenon. So we studied how these natural phenomenon affect urban flood risk. We used a system dynamics approach using feedback causal map as a suitable method for modeling natural phenomena and projections of system futures [8]. We simulated the model by setting scenarios and analyzed the influence of land use by population growth on urban flood risk. 
In order to reduce the risk of flooding in urban areas, we propose policies and directions for land use regulation in new cities that are undergoing urbanization by population growth.

\section{SYSTEM DYNAMICS}

System dynamics is a model that provides easy understanding of dynamic system behavior through feedback process [1]. System dynamics was developed by Forrester and is used in various fields as a causal network methodology. System dynamics is more efficient and simpler than traditional system analysis methods. In addition to system dynamics, there are Bayesian networks, causal Bayesian networks, and PLS structural equations in the causal network methodology [9]. However, system dynamics is an appropriate method because feedback process is essential to express natural phenomena such as population growth and urban expansion.

The basic of system dynamics is an understanding of the feedback process within the system [10]. In the feedback loop, past behavior affects future behavior. In natural phenomena, there are positive and negative relationships between each factor. These relationships form positive loop or negative loop and can be expressed in system dynamics as well. Expressed positive and negative loops are connected to form a system. These feedback causal loops are represented by a stock-flow diagram in system dynamics. A stockflow diagram consists of four basic components; stock variables, flow variables, connectors, and converters.

In order to develop the simulation model of system dynamics described above, the process as shown in Fig. 1 is required [11]. First, define the problem, and create a causal loop. Then, the stock-flow model is created according to the causal loop and the simulation is performed. After that, based on the simulation results, we evaluate the validity of the model and apply it to policy analysis. Feedback components interact with each other, and entire process is carried out.

\section{SD MODEL ARCHITECTURE}

\subsection{Classification of land use}

Before designing the system dynamics model, it was necessary to classify land use according to permeable. So Yangsan City where the population is increasing as a satellite city of Busan

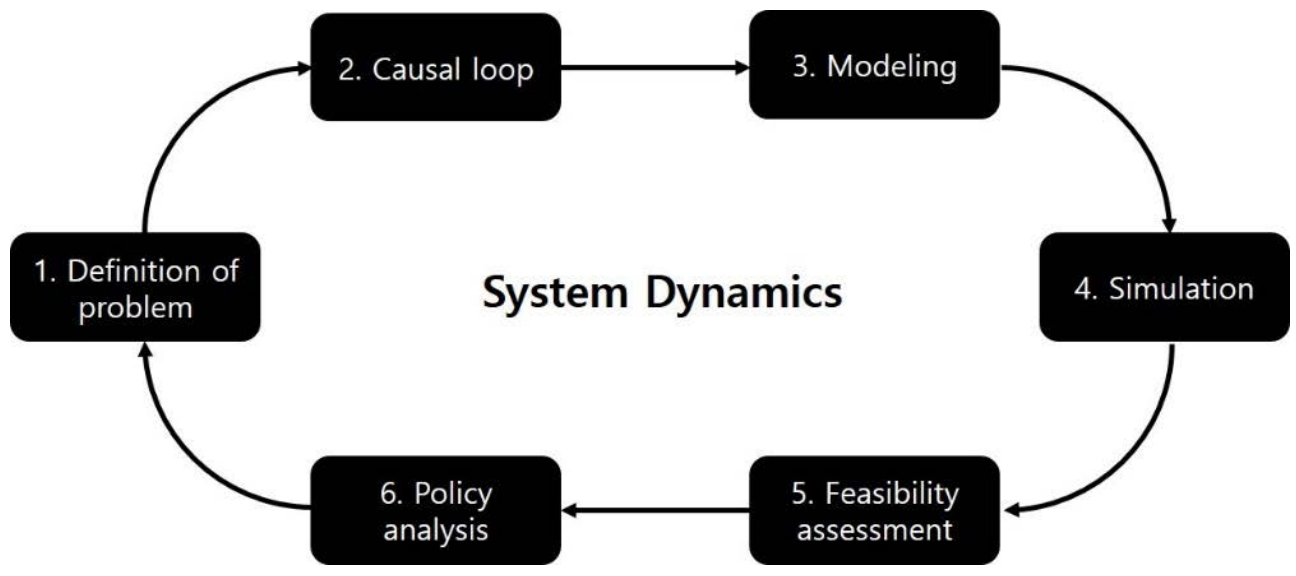

Figure 1: System dynamics process [11]. 
Metropolitan City was selected as a target area. Yangsan is a suitable area where urbanization and flooding are occurring together. In this reason, land use of Yangsan was classified by calculating the households and population data from 2010-2015, and the initial data was set as Yangsan's data from 2010-2015.

Table 1 shows the categories of land use classification in Yangsan City statistical data based on the city center and the outer city, and then classified according to permeable. The criterion of the inner and outer city was judged by the definition of category, and the permeability was classified by land property. In this paper, the target area is set as the area of the city center. The pervious area in the city center is set as railroad, river, embankment, water supply, park, athletic field, amusement park, historical site, and the impervious area in the city center is set as building, factory, school, parking lot, gas station, warehouse, road, religion. Such categorization was classified according to land characteristics of city.

The categories classified in the statistical data were grouped into seven land use categories by integrating the similar parts(land use characteristics and permeability). As shown in Table 2, the building site (building), factory site (factory, school, warehouse), traffic site (parking lot, gas station, road), water resource site (river, embankment, water supply), green site (park, amusement park), other pervious site (railroad, athletic field, historical site), other impervious site (religion).

\subsection{Causal loop}

Fig. 2 shows a causal map of population, land use(impervious and pervious site growth), impervious area ratio, and urban flood risk including reclassified land use categories, as shown in Table 2. The overall feedback loop is a positive feedback loop that increases in population and impervious area ratio. From a population perspective, population growth will lead to the expansion of the city center, and the rate of land growth per population will vary

Table 1: Classification of land use according to permeable.

\begin{tabular}{|l|l|l|}
\hline \multirow{2}{*}{ Out of city center } & Pervious area & $\begin{array}{l}\text { Field, rice field, orchard, ranch, forest, drain, } \\
\text { pond, fish farm, cemetery, etc. }\end{array}$ \\
\cline { 2 - 3 } City center & Impervious area & \\
\hline Pervious area & $\begin{array}{l}\text { Railroad, river, embankment, water supply, } \\
\text { park, athletic field, amusement park, historical } \\
\text { site }\end{array}$ \\
\cline { 2 - 3 } & Impervious area & $\begin{array}{l}\text { Building, factory, school, parking lot, gas } \\
\text { station, warehouse, road, religion }\end{array}$ \\
\hline
\end{tabular}

Table 2: Reclassification of the land use category.

\begin{tabular}{|l|l|}
\hline Building site & Building \\
\hline Factory site & Factory, school, warehouse \\
\hline Traffic site & Parking lot, gas station, road \\
\hline Water resource site & River, embankment, water supply \\
\hline Green site & Park, amusement park \\
\hline Other pervious site & Railroad, athletic field, historical site \\
\hline Other impervious site & Religion \\
\hline
\end{tabular}




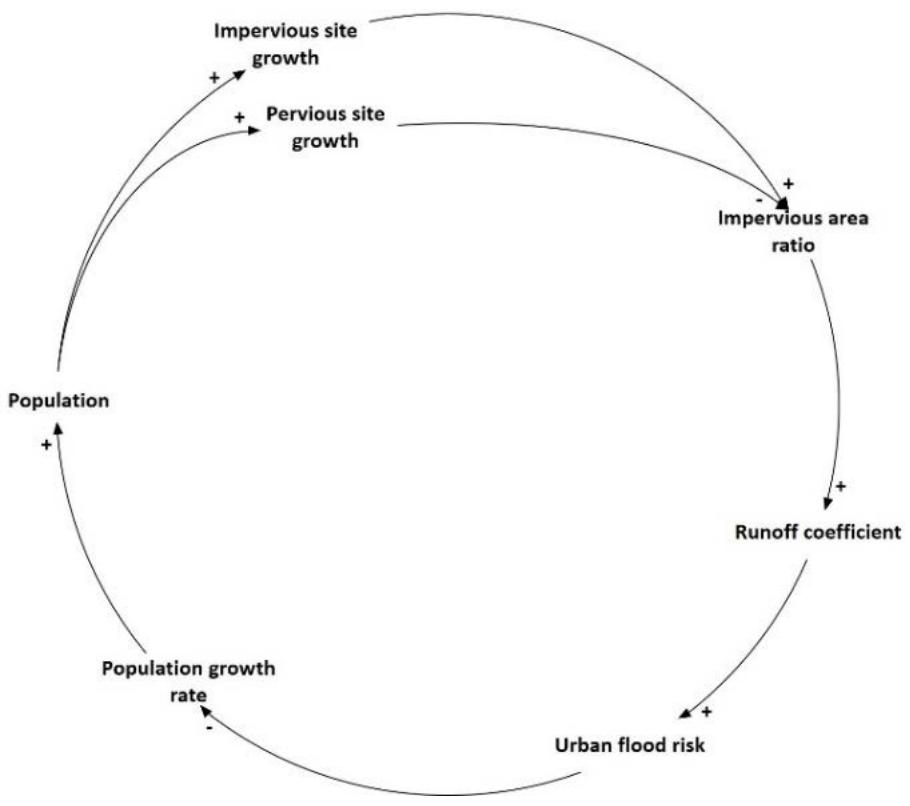

Figure 2: Causal map for SD modelling.

by land use categories. Therefore, the area of each land use category is widened in proportion to the population increase, and the urban area also increase. So increased land is classified according to permeability and is used to calculate impervious area ratio. The impervious area ratio is used to calculate the urban runoff coefficient. At this point, we assumed that it is not affected by hydrological properties [12], [13]. Once the runoff coefficient for the population increase is calculated, it is expressed as the urban flood risk in the city center. Eventually, the urban flood risk affects the population growth rate, and the population growth rate increases or decreases. That is forming a feedback loop which regulates population growth.

\subsection{Design SD model}

Based on the causal map (Fig. 2), designed the SD model to evaluate urban flood risk variability due to the urban expansion as shown in Fig. 3. We used Stella, a system dynamics modeling program. Fig. 3 provides a more detailed view of positive feedback on causal maps. Population growth is calculated together with the per capita land increase of seven land use categories, thus expanding the urban area. Percentage of impervious area, runoff coefficient, and urban flood risk are calculated with the increased land. The population growth rate and the population decrease rate are affected by the urban flood risk. The urban area part assumes that the green site will be developed as a building site, a factory site, and a traffic site if the area in the center of city becomes more than $35 \%$ of the total area of the city.

Table 3 shows the correlation from the impervious area ratio to the population in the SD model design (Fig. 3). The correlation between the impervious area ratio and the runoff coefficient is derived by adding a little data to the data of Driscoll (1983) by Schueler [12], [13]. It is based on the assumption that this relationship is not affected by the hydrological factors. The correlation between urban flood risk, population growth rate, and population 


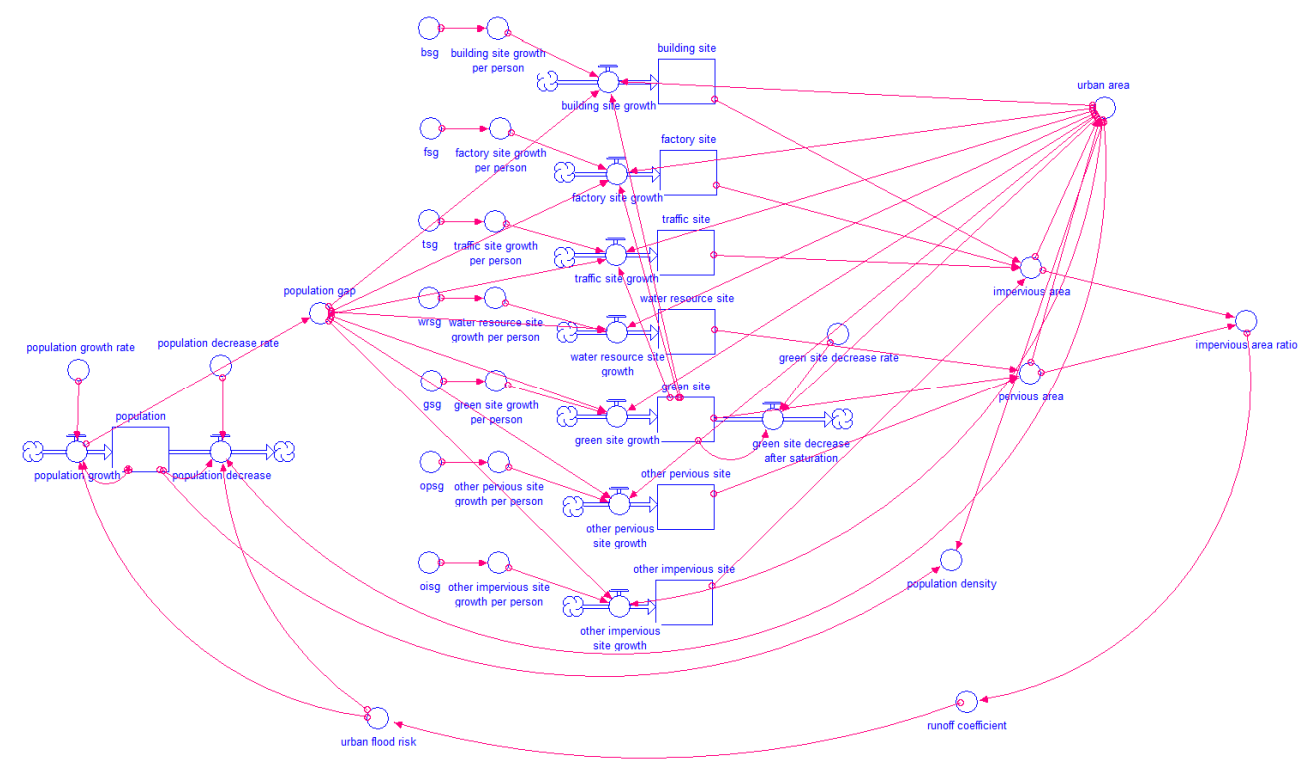

Figure 3: SD model for evaluate urban flood risk variability.

Table 3: Correlation used in SD model.

\begin{tabular}{|c|c|}
\hline $\begin{array}{l}\text { Impervious area ratio: } \\
\text { Runoff coefficient }\end{array}$ & $\begin{array}{l}\text { Runoff coefficient } \\
=0.0091 * \text { Impervious area ratio*100-0.00204 [12], [13] }\end{array}$ \\
\hline $\begin{array}{l}\text { Runoff coefficient: } \\
\text { Urban flood risk }\end{array}$ & $\begin{array}{l}\text { Urban flood risk } \\
=10^{\wedge} \text { Runoff coefficient }\end{array}$ \\
\hline $\begin{array}{l}\text { Urban flood risk: } \\
\text { Population growth rate }\end{array}$ & Population growth rate $[1+(5$-Urban flood risk $) / 10]$ \\
\hline $\begin{array}{l}\text { Urban flood risk: } \\
\text { Population decrease rate }\end{array}$ & $\begin{array}{l}\text { (city center area }<35 \% \text { of the city's total area) } \\
\text { Population decrease rate }[1+(\text { Urban flood risk-5)/10) }] \\
(\text { city center area }>35 \% \text { of the city's total area }) \\
\text { Population decrease rate }[1+2 *(\text { Urban flood risk- } 5) / 10)]\end{array}$ \\
\hline
\end{tabular}

decrease rate is assumed to increase population growth rate and to decrease population decrease rate when urban flood risk is less than five. In addition, if the center area of the city becomes more than $35 \%$ of the total area of the city, it is assumed that the population decrease rate increase double.

\section{SIMULATIONS RESULTS AND DISCUSSION}

\subsection{Site growth rates and sensitivity analysis}

The initial site growth rates for simulating the designed SD model were derived from Yangsan City's statistical data. The average growth rate of the population and land expansion from 2010 to 2015 are calculated, and the urban expansion rate per capita is set as the initial site growth rates (Table 4). The initial site growth rates are the building site 
(43.39 $\mathrm{m}^{2} /$ person), factory site $\left(55.88 \mathrm{~m}^{2} /\right.$ person), traffic site $\left(43.54 \mathrm{~m}^{2} /\right.$ person $)$, water resource site $\left(1.37 \mathrm{~m}^{2} /\right.$ person), green site $\left(14.78 \mathrm{~m}^{2} /\right.$ person), other pervious area $(12.00$ $\mathrm{m}^{2} /$ person), and other impervious area $\left(1.74 \mathrm{~m}^{2} /\right.$ person).

The sensitivity of urban flood risk to land use change was analyzed. Sensitivity analysis was conducted on four categories (building, factory, traffic, and green) where the rate of land expansion per person is large. Sensitivity was measured by changing the site growth rates by lowering $10 \%$ to each category. Figs 4-7 show the sensitivity analysis results for the building site, factory site, traffic site, and green site, respectively. Based on these results, the sensitivity of urban flood risk in 50 years is compared and the sensitivity is quantified in Table 5. Sensitivity analysis results showed building site (0.16), factory site (0.22), traffic site $(0.16)$ and green site $(0.11)$.

Table 4: Initial site growth rates.

\begin{tabular}{|c|c|c|c|c|c|c|c|}
\hline Site & Building & Factory & Traffic & $\begin{array}{c}\text { Water } \\
\text { resource }\end{array}$ & Green & $\begin{array}{c}\text { Other } \\
\text { pervious area }\end{array}$ & $\begin{array}{c}\text { Other } \\
\text { impervious area }\end{array}$ \\
\hline $\begin{array}{c}\text { Growth rate } \\
\left(\mathrm{m}^{2} / \text { person }\right)\end{array}$ & 43.39 & 55.88 & 43.54 & 1.37 & 14.78 & 12.00 & 1.74 \\
\hline
\end{tabular}

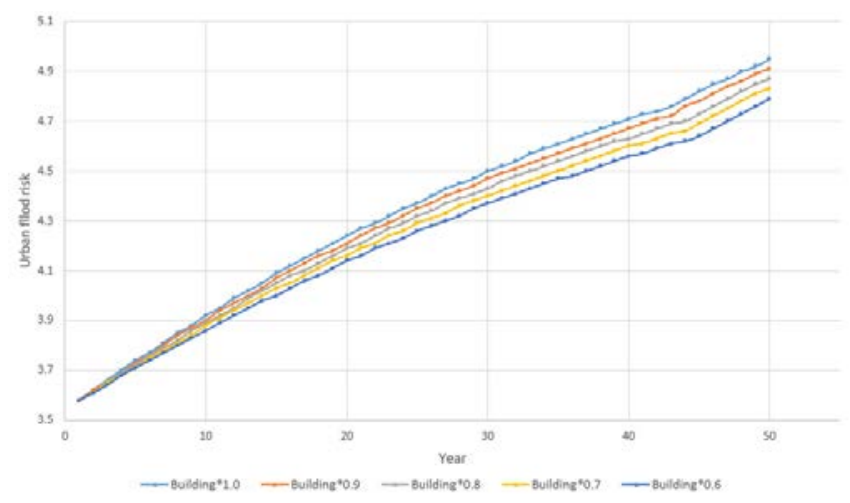

Figure 4: Sensitivity analysis for building site.

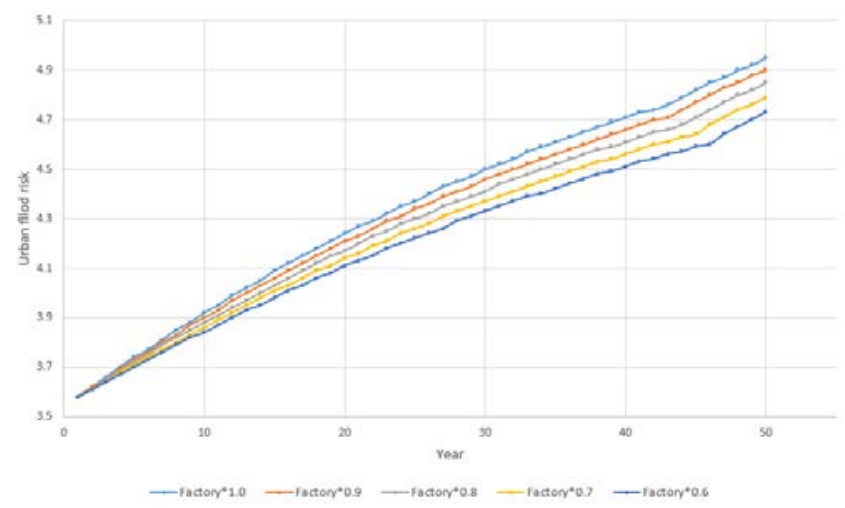

Figure 5: Sensitivity analysis for factory site. 


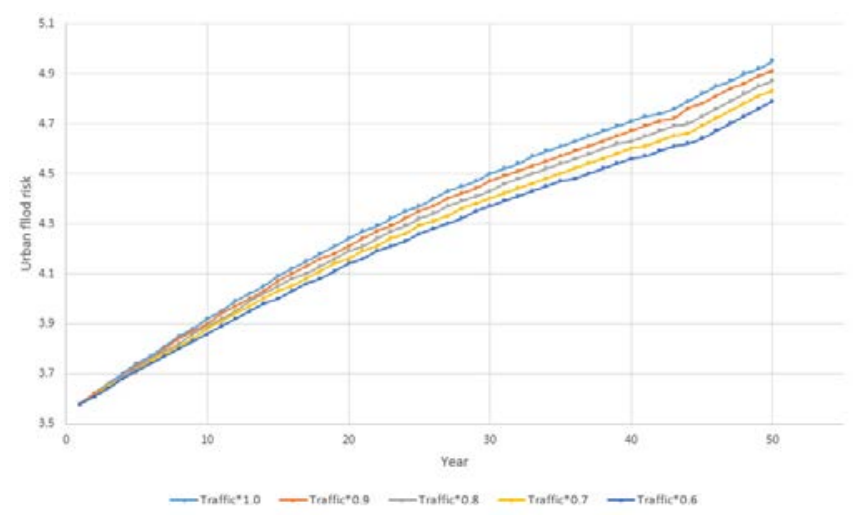

Figure 6: Sensitivity analysis for traffic site.

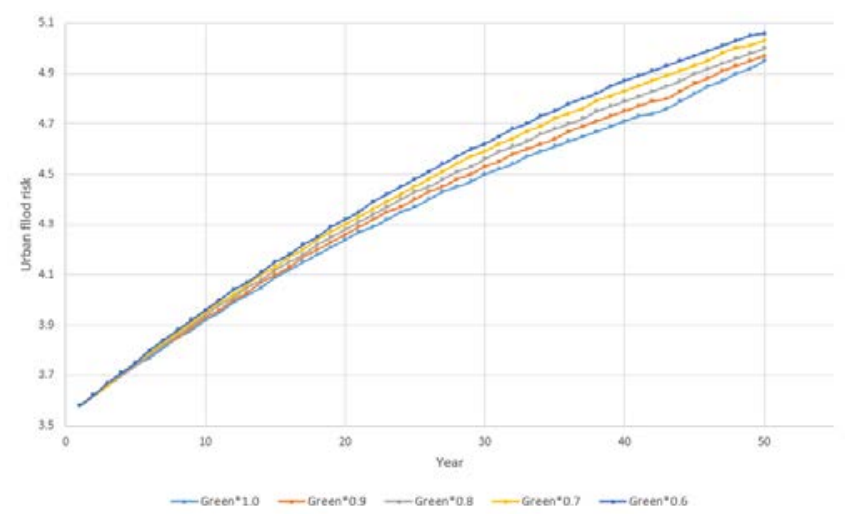

Figure 7: Sensitivity analysis for green site.

Table 5: Sensitivity analysis results for building, factory, traffic, and green site.

\begin{tabular}{|c|c|c|c|c|}
\hline Site & Building & Factory & Traffic & Green \\
\hline Sensitivity & 0.16 & 0.22 & 0.16 & 0.11 \\
\hline
\end{tabular}

\subsection{Scenario simulation results and sensitivity analysis}

Sensitivity analysis of the initial simulation showed the sensitivity of the land use change to urban flood risk. Based on the sensitivity of site growth rates, several scenarios were set up to conduct sensitivity analysis.

Table 6 shows four scenarios in which the amount of land increase per capita is different. Scenario A and Scenario B are scenarios in which the most sensitive factory site (impervious area) and the green site, which is pervious area, are changed. The conditions of Scenario A are $10 \%$ reduction in factory site growth rate, the reduction of factory site growth rate changes to green site growth rate, and the expansion rate of the city center is not changed. Scenario B is a case that the factory is decreased by $10 \%$ and green is increased by $10 \%$, and the 
Table 6: Simulation scenario cases.

\begin{tabular}{|l|c|c|c|c|c|c|}
\hline & Building & Factory & Traffic & Green & Etc. & $\begin{array}{c}\text { Total } \\
\text { expansion }\end{array}$ \\
\hline Scenario A & No change & $-10 \%$ & No change & + Factory $10 \%$ & No change & No change \\
\hline Scenario B & No change & $-10 \%$ & No change & $+10 \%$ & No change & $-2.4 \%$ \\
\hline Scenario C & $-3 \%$ & $-4 \%$ & $-3 \%$ & $\begin{array}{c}+ \text { Building } 3 \% \\
+ \text { Factory } 4 \% \\
+ \text { Traffic } 3 \%\end{array}$ & No change & No change \\
\hline Scenario D & $-10 \%$ & $-10 \%$ & $-10 \%$ & $-10 \%$ & $-10 \%$ & $-10 \%$ \\
\hline
\end{tabular}

expansion rate of the city center is decreased by $2.4 \%$. In Scenario C, when the rate of land increase per person (building, factory, traffic) decreases by $10 \%$, the weight according to the sensitivity is given. Building site growth rate is decreased by $3 \%$, factory site growth rate is decreased by $4 \%$, traffic site growth rate is decreased $3 \%$, and green site growth rate is increased by the decrease of the permeable area. So that the expansion rate of the city center does not change. Scenario D is a case of decreased $10 \%$ of the expansion rate of the city center.

Figs 8-11 show the sensitivity analysis results for Scenario A, Scenario B, Scenario C, and Scenario D, respectively. The sensitivity analysis for the scenarios compares the rate of increase in urban flooding risk, until the city center becomes $35 \%$ of the total urban area. The average variation of urban flood risk increase rate was used as an index to compare sensitivity. The results were as follows: Scenario A (-0.0041), Scenario B (-0.0021), Scenario $\mathrm{C}(-0.0039)$, and Scenario D (-0.0015). Scenario A (factory site growth rate is decreased by $10 \%$, the reduced factory site growth rate changes to green) was the most effective scenario for reducing the urban flood risk increase rate. The second most effective scenario was Scenario C, which weights according to sensitivity. In conclusion, it is more effective to reduce the rate of land expansion according to the sensitivity to the urban flood risk than to reduce the expansion rate of the city center.

\subsection{Discussion}

In order to reduce the rate of increase of urban flood risk, it was shown through scenario simulation that it is effective to reduce the land expansion rate by the sensitivity according to

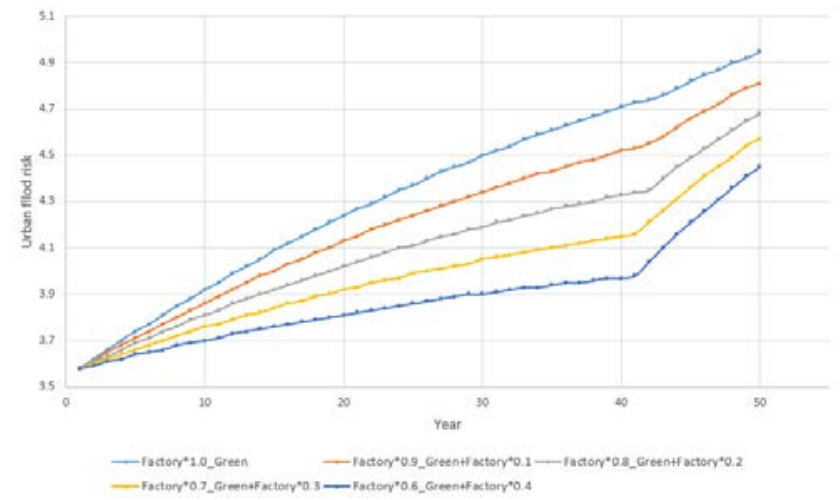

Figure 8: Simulation results (Scenario A). 


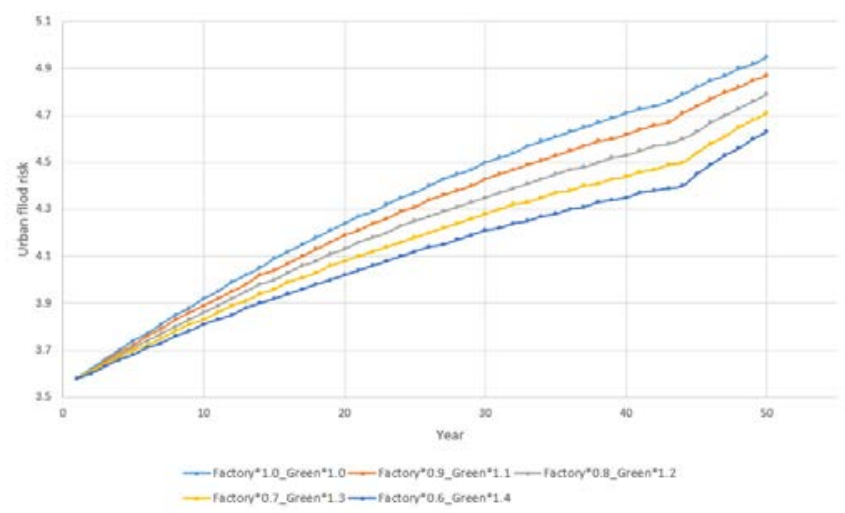

Figure 9: Simulation results (Scenario B).

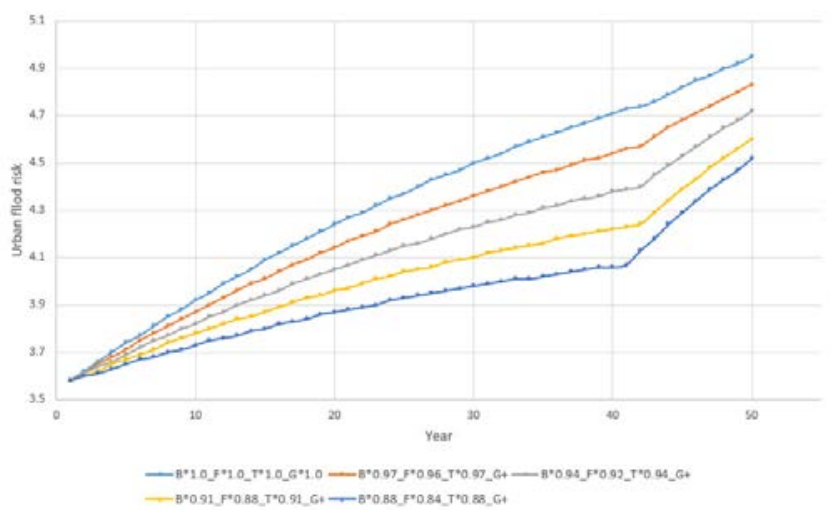

Figure 10: Simulation results (Scenario C).

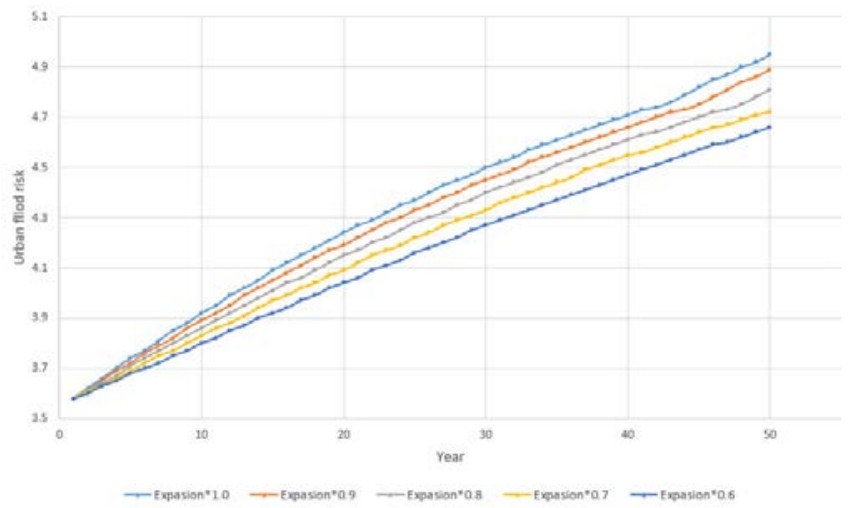

Figure 11: Simulation results (Scenario D). 
Table 7: Sensitivity analysis results for Scenario A to D.

\begin{tabular}{|c|c|c|c|c|}
\hline & Scenario A & Scenario B & Scenario C & Scenario D \\
\hline \multirow{4}{*}{$\begin{array}{c}\text { Urban flood risk } \\
\text { increase rate (/year) }\end{array}$} & 0.0274 & 0.0274 & 0.0274 & 0.0274 \\
\cline { 2 - 5 } & 0.0231 & 0.0257 & 0.0236 & 0.0260 \\
\cline { 2 - 5 } & 0.0183 & 0.0236 & 0.0195 & 0.0244 \\
\cline { 2 - 5 } & 0.0852 & 0.0212 & 0.0157 & 0.0228 \\
\cline { 2 - 5 } & 0.0110 & 0.0190 & 0.0120 & 0.0216 \\
\hline Average variation & -0.0041 & -0.0021 & -0.0039 & -0.0015 \\
\hline
\end{tabular}

the land use rather than to reduce the expansion rate of the city center. This result shows that the regulation of the land use, which is highly sensitive to the risk of urban flood, is more effective than the regulation of the expansion rate of the city center. Also, the sensitivity regulation has been somewhat effective in slowing down the increase in urban flood risk. If the amount of data input to the SD model and the more detailed impervious area for each land use are calculated, the accuracy of the model can be further increased. Therefore, it is necessary to further study the relationship between the impervious area and the risk of urban flood, reflecting data on the irrigation area in detail.

\section{SIMULATIONS RESULTS AND DISCUSSION}

The scenario conclusions of the SD model were derived as follows. First, we estimated the impervious area ratio and the urban flood risk due to the urban expansion and land use. Scenario B and Scenario D, which reduce the expansion rate of the city center, were found to have sensitivity of -0.0021 and -0.0015 , respectively, for an increase in urban flood risk. The sensitivity of Scenario A, which reduces the expansion rate of the Factory site with high sensitivity, to the risk of urban flood was -0.0041 . Sensitivity to the increased risk of urban flood in Scenario C, which weights according to sensitivity, was -0.0039 . In conclusion, to reduce the rate of urban flood risk increase, it was effective to regulate land use with high sensitivity to risk increases.

\section{ACKNOWLEDGEMENT}

This work is financially supported by Korea Ministry of Land, Infrastructure and Transport (MOLIT) as U-City Master and Doctor Course Grant Program.

\section{REFERENCES}

[1] Shuster, W.D., Bonta, J., Thurston, H., Warnemuende, E. \& Smith, D., Impacts of impervious surface on watershed hydrology: A review. Urban Water Journal, 2(4), pp. 263-275, 2005.

[2] Ahmad, S. \& Simonovic, S.P., System dynamics modelling of reservoir operations for flood management. Journal of Computing in Civil Engineering, 14(3), pp. 190-198, 2000.

[3] Schmitt, T.G., Thomas, M. \& Ettrich, N., Analysis and modeling of flooding in urban drainage systems. Journal of Hydrology, 299(3), pp. 300-311, 2004.

[4] Schreider, S.Y., Smith, D. \& Jakeman, A., Climate change impacts on urban flooding. Climatic Change, 47(1), pp. 91-115, 2000.

[5] Ahn, J.H., An analysis on the variation of hydrometeorology due to land use change in urban area. Proceedings of the Korea Water Resources Association Conference, pp. 627-631, 2006. 
[6] Zimmermann, E., Bracalenti, L., Piacentini, R. \& Inostroza, L., Urban flood risk reduction by increasing green areas for adaptation to climate change. Procedia Engineering, 161, pp. 2241-2246, 2016.

[7] Shim, J.H. \& Kim, J.E., An analysis on the interrelationship between land-use characteristics and damages caused by natural hazards. Journal of the Korea Academia-Industrial Cooperation Society, 13(9), pp. 4319-4325, 2012.

[8] Winz, I., Brierley, G. \& Trowsdale, S., The use of system dynamics simulation in water resources management. Water Resources Management, 23(7), pp. 1301-1323, 2009.

[9] Lee, J.H., Kim, K.D., Hong, H.N., Cho, Y.R. \& Cho, H.B., Research trends and case studies on disaster diffusion model based on causal network. Journal of the Korean Institute of Communication Sciences (Information and Communication), 29(5), pp. 42-49, 2012.

[10] Park, M.S., Son, B.S., An, S.J. \& Lee, H.S., A system dynamics approach to construction policymaking: Evaluating the Singaporean government's productivity policies. Journal of Architectural Institute of Korea, 21(5), pp. 123-134, 2005.

[11] Jeong, E.S., Lee, S.J., Lee, J.H. \& Kim, Y.O., Current status of watershed management model of system dynamics. Journal of Korea Water Resources Association, 45(3), pp. 28-40, 2012.

[12] Schueler, T.R. (ed.), Controlling Urban Runoff: A Practical Manual for Planning and Designing Urban BMPs, Water Resources Publications, 1987.

[13] California Department of Transportation, Runoff coefficient evaluation for volumetric BMP sizing, Online. www.dot.ca.gov/design/hsd/guidance/CTSW-TM-15-312_03_ 01-Runoff_Coeff_for_Vol_BMP_Sizing.pdf. Accessed on: 9 May 2018. 